\title{
Confrontation of the Structuring Logic Previous Question, Next Question of the Teacher in the Formulation of a Statement in Mathematics to that of the Student in the Resolution of the Problem Posed
}

\author{
Anon N'Guessan \\ Lecturer in Educational Sciences \\ N'Goran N'Faissoh Franck Stephane \\ $\mathrm{PhD}$, Criminal Psychology, Felix \\ Houphouet-Boigny University (Abidjan)
}

\section{Abstract}

This study aims to analyze the correlation of the student's progress in solving a given problem with the logic of the teacher in the layout of the questions asked. The research was conducted in the government's secondary schools and colleges in the district of Abidjan and involved 453 participants, including 423 student and 30 teachers. The data was collected based on a survey questionnaire and then annalysed based on a quantitative and qualitative point of view. The results of the study focused on the concordance of the student's progress in solving a given problem with the teacher's logic in the layout of the questions asked. The study shows that students' performance in mathematics is not dependent on how often they follow the order of the question in the statement.

Keywords: previous question, next question, teacher, mathematical statement, solving a problem

\section{Introduction}

Mathematics is known as a black sheep for many pupils and students because of the difficulties they experience to appropriate it. The explanatory factors for these difficulties are endogenous and / or exogenous because they are psychological, ontogenetic, epistemological, social, didactic and pedagogical. But didactic and pedagogical factors occupy an important position in this list and the evaluative practices of teachers constitute an aspect not to be neglected.

In fact, assessment, which is an essential component of the teaching-learning process, holds a significant position in the causes that affect student performance in numerous 
disciplines, particularly in mathematics. As Legendre (2001) says, "Teaching, learning and assessment are not considered in sequence, as distinct moments from the pedagogical process, but rather in their dynamic interaction within this process". Gerard and Roegiers (2011) make the same observation by saying that "the teachinglearning process has resolutely become a teachinglearning-assessment process". However, the consistency between these three components creat many difficulties. This is noted in the words of Fran^oise Munck (2014) according to which "teachers often regret that current assessments resolves in findings which only make it difficult for students to learn about their progress and insufficiently about the nature of their errors. They also deplore not allowing certain pupils to show in evaluation what they know how to do, the latter being too often confronted with situations which require learning which they have not yet constructed".

Note that an effective learning evaluation requires an instrument that allows the collection of relevant, valid and reliable information. In other words, an instrument that does not have these qualities can significantly affect the student's production because it can induce cognitive biases in the student and impair the teacher's judgment. As Barbier (1984) defines it, "to evaluate is to pronounce a value judgment by establishing a gap between a referent (what we are referring to, an ideal, a standard, an objective, even a referential that we can qualify quickly catalog of available references) which is not necessarily stable, stabilized or expressed, deposited on a support, and a summary (a performance, a student's copy, an oral or any production, durable or not)". This definition highlights the confrontation between the two main actors (pupil, teacher) of a teaching-learning situation where each of them develops a strategy specific to him.

Thus, the development and communication of the referral upstream of the referral request becomes essential (Fagnant A. \& al, 2017). Because this confrontation is marked by the dominant position of the master as pointed out by Munck F, Pilard P. and Terrien D. (2014), for whom "Evaluation is a moment of meeting between the evaluator (the teacher) and the assessor (the student) or, more precisely between the assessor and the production of the assessed. This meeting is unbalanced. It is indeed the teacher who creates the subject, sets his expectations and analyzes the production. The pupil can find himself in the position of having to produce while trying to respond to more or less nebulous expectations for him, position to say the least uncomfortable ". This implies that any failure at the level of the teacher in the development of the assessment will have a negative impact on the student's production. Because the ability to solve a problem indicates a good level of mastery of the knowledge on which the statement relates. This is why problem solving is central to mathematics education programs.

Indeed, "Problem solving is the main criterion for mastering knowledge in all areas of mathematics, but it is also the means of ensuring its appropriation which guarantees its meaning." (Couchoux C. 2005). However, only a well structured and syntactically 
correct statement can ensure a good investment and a consolidation of the learner's achievements when solving a problem. However, many problem statements contain errors and even inconsistencies in the organization of the information they contain. This is sometimes due to the difficulty for some teachers to build valid instruments due to a lack of skills in the evaluation of learning. Indeed, many teachers are not trained in the methods of assessing learning. These are even more numerous in subSaharan Africa.

Thus, the evaluation practices of the majority of teachers in secondary and higher education establishments in Cote d'Ivoire are modeled on those that were applied by their teachers during their school and university courses. It is noted that often no clearly defined criterion is taken into account in the evaluation of learning. The development of an effective evaluation presupposes the definition of relevant criteria with appropriate indicators. As a result, Brassard (2012) formulated six criteria that should be met in order to be able to design effective assessments, which measure what they are supposed to measure, that is, learning objectives. Among these criteria is the use of clear questions and instructions in order to properly formulate our expectations for our students. This presupposes consistency in the arrangement of these questions.

These should be posed in an order that can facilitate the student's development of effective strategies for providing adequate responses. To understand the factors behind a student's poor performance during an assessment, a list of the main diagnoses that can be inferred was drawn up by Musial, M., Pradere, F., \& Tricot, A. (2012) who indicate that the student may not be able to complete an activity that is asked of him if he "mobilizes other knowledge instead". More explicitly, "The student tries to complete the task but does not succeed because the knowledge that he mobilizes is not relevant. In this situation, the diagnosis can be directed towards a very superficial element: it is a word of the statement, a simple aspect of the instruction, which led him to mobilize an inappropriate knowledge ". This shows that certain aspects of the statement of the problem posed can induce understanding bias in the person being evaluated. Indeed, the results of the work of certain authors such as Coquin and Viennot (2000) have shown that the same arithmetic problem can be associated with different success rates depending on the formulation characteristics of its statement.

Fayol, Abdi and Gombert (1987) have also shown that presenting arithmetic problems orally, the question of which is placed at the head rather than classically at the end of the sentence, improves resolution performance. There is often a failure when the activity carried out by the subject is out of phase with the assigned task or when the subject does not succeed in mobilizing all the resources (psychological, physiological, neuro-informational, etc.) necessary to achieve the prescribed task.

Note that the task indicates what is to be done, the activity indicates what is done. Thus, the task and the activity materialize the teacher-learner confrontation. 
These are building blocks of the teaching-learning dynamic. And it happens in a school problem that the gap between the assigned task and the perception of it by the student is large. "By problem we must understand, in the broad sense given to it by the psychologist, any situation in which we must discover relationships, develop activities of exploration, hypothesis and verification, to produce a solution." (VERGNAUD G., 1986). A mathematic problem can be defined as a statement about objects and structures, requiring a subject to build coherent reasoning to highlight the relationships between these elements, in order to achieve a specific goal. In class, the tasks assigned are generally didactic problems. For De VANSSAY S. and De BLAVOUS S. (2010), a problem in mathematics is therefore for the student a situation in which he must answer the question asked using mathematical tools and / or intellectual skills used in mathematics. He carries out this task using the information given, explicitly or not, in the statement and his experience in problem solving. According to the Definitions Dico (2011), a problem of this kind must expect three basic elements: the data necessary to solve it (always explicit), the method or the relationship between the data (which is what student must verify) and the expected result (which is achieved after following certain reasoning rules and assumptions or even hypotheses arising from the data). Several elements are involved in solving a problem. Among the variables likely to influence, problem solving, special attention must be paid to the formulation of statements. Even if it is difficult to dissociate this formulation from the relational structures themselves, certain forms of statements seem to make the structure of a problem clearer than others, and therefore easier to represent for the subject (Jean Brun, 1990). A problem situation in the school environment inevitably generates an interpretation on the part of the student. This interpretation of the problem posed leads to the subject's representation of the perceived task and results in all of the procedures implemented to build the solution. To solve the problem, it is necessary to build a good representation of the model and therefore modify its interpretation (initial, intermediate and final states) to match the space of the problem and the space of the task. (Mostefaoui K., 2016). This leads to the following questions and conjectures:

\section{Research questions, objectives and hypotheses}

\section{Research questions}

Does the arrangement of the questions in a given problem during a mathematics assessment influence the solving strategy deployed by the student to build the expected solution?

More precisely:

Can the order in which the questions are asked in a mathematical problem favor or hinder the student's success in building the solution?

Can the order in which the questions are asked in a math problem widen the gap between the assigned task and the student's perception of it? 
Can the succession of questions in the statement of a problem cause a state of anxiety in the evaluated person, when it does not coincide with the path adopted by the latter?

By adopting an approach other than that planned by the teacher, can the student achieve the result expected by his teacher?

These questions shed light on the objectives of this study.

\section{Research objectives}

\section{Main objective:}

This study aims to analyze the correlation of the student's progress in solving a given problem with the teacher's logic in the arrangement of the questions asked.

\section{Specific objectives:}

It is a question during this study of:

Define the metacognitive strategies implemented by the student to solve a given mathematical problem.

Describe the procedure for the teacher to develop a mathematical problem.

Show that the gap between the assigned task and the student's perception of the task is sometimes large.

Show that the succession of questions in the statement, when it does not coincide with the student's progress, can widen the gap between the prescribed task and the perceived task.

Establish a link between the poor performance in mathematics and the gap between the logic of resolution induced by the statement and that adopted by the student.

Research hypotheses

Main hypothesis

Divergences sometimes arise between the student's logic in solving a given mathematical problem and that of the teacher in structuring the statement. And this is not without consequences for the student's performance.

\section{Secondary hypothesis 1}

The divergence between the teacher's logic in the structuring "previous question, next question" of the statement of a mathematical problem and that of the student in the resolution of this problem is a source of psychological disturbance in the latter.

\section{Secondary hypothesis 2}

The order of the questions in the statement of a mathematical problem, when it does not coincide with the student's cognitive path logic in solving this problem, widens the gap between the prescribed task and the perceived task. 


\section{Secondary hypothesis 3}

The poor performance in mathematics is due to the discrepancy between the logic of resolution induced by the statement and that of the student facing the problem posed.

To verify these hypotheses, the following approach was adopted.

\section{Methodology}

\section{Study population}

The target population is all secondary school students from Cote d'Ivoire. But given the limited means at our disposal, the study population is all the students of public high schools and colleges in the Abidjan district. To do this, the following establishments were chosen: Classical high school of Abidjan, Holy Mary high school of Cocody (Abidjan), Municipal high school of Abobo (Abidjan) Modern high school of Port-Bouet (Abidjan) Municipal high school of Yopougon (Abidjan), Modern high school of d'Anyama.

\section{Study sample}

\section{Sampling method}

As mentioned above, the means at our disposal are quite limited. In addition, the time available for this study is quite short. Therefore we opted for a reasoned choice empirical sample. While this method offers the advantage of easy access to students, it is difficult to generalize the results to the study population.

Indeed, this type of sample is not always representative of the population. However, the investigators were asked to make relevant choices of subjects among the students present in the class. The selection of subjects was made from good students, average students and those in difficulty in mathematics. This can improve representativeness within the population.

\section{Description of the sample}

We recall that the study sample is empirical precisely with reasoned choice because the selection of subjects took into account their level of performance in mathematics. This sample is made up of pupils from high schools and colleges in the Abidjan district of the fourth, third, second, first and final grades. For the second cycle, the respondents were selected from series $\mathrm{A}^{1}, \mathrm{C}^{2}$ and $\mathrm{D}^{3}$.

The sample consists of a total of 423 students. In addition to these, 30 mathematics teachers working in the schools selected for this study were selected to be asked about their procedures for developing problem statements in mathematics.

\footnotetext{
${ }^{1} \mathrm{~A}=$ Literature or letters department

${ }^{2}$ Sciences department

${ }^{3}$ Sciences department
} 


\section{Data collection instrument}

To be able to reach a large number of subjects, a survey questionnaire was used. The choice of this type of instrument obeys the idea of making a quantitative analysis. The questionnaire includes both closed and open questions.

Open questions are introduced to allow subjects to answer freely and above all to encourage a wealth of answers. This made it possible to carry out qualitative analyzes of certain responses.

\section{Administration of the questionnaire}

The questionnaire was administered to the students by teachers whom we contacted. These investigators selected students from classes they hold for the 2019-20 school year. As indicated above, the investigating teachers selected students on a trial basis taking into account the levels of difficulty in mathematics. The sample then contains pupils in difficulty, average pupils and those with a high level of performance in mathematics.

\section{Data processing and analysis}

The collected data was entered into a matrix created with SPSS 22.0 software. The information entered is the answers to the closed questions. This software was logically used to perform quantitative (descriptive, inferential) analysis of the data. The open questions were used for the qualitative analysis.

\section{Results}

\section{Socio-demographic characteristics of the students surveyed}

According to the results of this study, the majority (57.5\%) of the students interviewed are male. However, there is a significant proportion (42.5\%) of girls. In addition, the vast majority $(89.7 \%)$ of students surveyed are made up of nonrepeaters. In other words, only $10.2 \%$ of the pupils surveyed are repeaters. The histogram below gives the form of the age distribution of the students who participated in this study. It shows that the average age is 16.81 years with a standard deviation of 1.791 . This gives a coefficient of variation, the value of which is $10.65 \%$, indicating that the series is homogeneous around the average. 


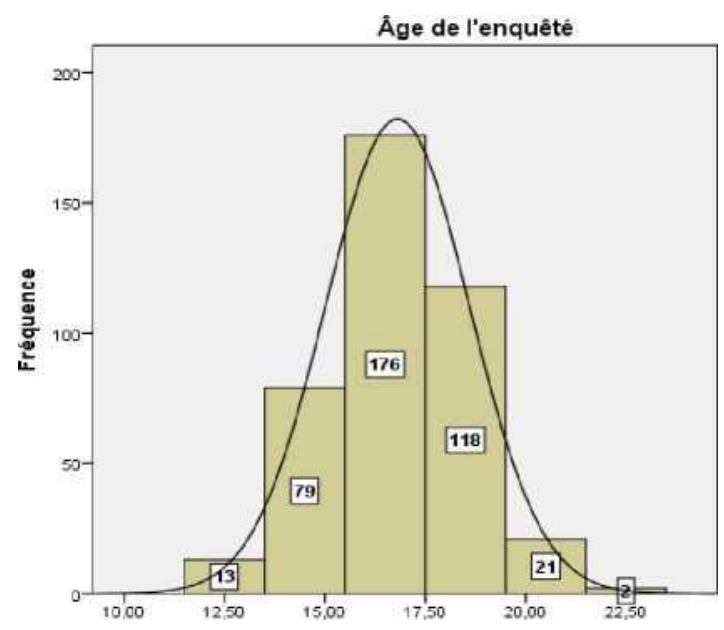

\section{Age de I'enquete}

Figure 1: Distribution of respondents by age

Source: Surveys, 2019

The mean $(=16.81)$, the median $(\mathrm{Me}=17)$ and the mode $(\mathrm{Mo}=17)$ of this distribution have substantially the same value. Therefore, it can be said that the distribution is symmetrical and follows a Gauss-Laplace curve.

Regarding the level of study, we note that the majority of the pupils questioned (58.29\%) are in the final year class of secondary schools. And the remaining $41.71 \%$ is distributed as follows: $16.34 \%$ in Second year classes and $13.66 \%$ in First year classes of secondary schools, $9.76 \%$ in final year classes and only $1.95 \%$ in second year classes of Junior high Schools.

Math performance

Performance level in mathematics

Le Robert (2003: 1902) defines performance as "the quantified result obtained in a competition". As for Legendre (1993: 977), he defines performance as "the result obtained by a person, during the accomplishment of a specific task whose execution obeys pre-established rules".

In general, performance in a discipline is materialized by the students' marks in this subject even if these are not sufficiently relevant to characterize their achievements. Grades in mathematics are therefore performance indicators in this discipline. As KALAMO A. (2010/2011) puts it, "performance necessarily refers to the production of a response during an event. If the scores are high, we will speak of high performance. Otherwise they will be low." 


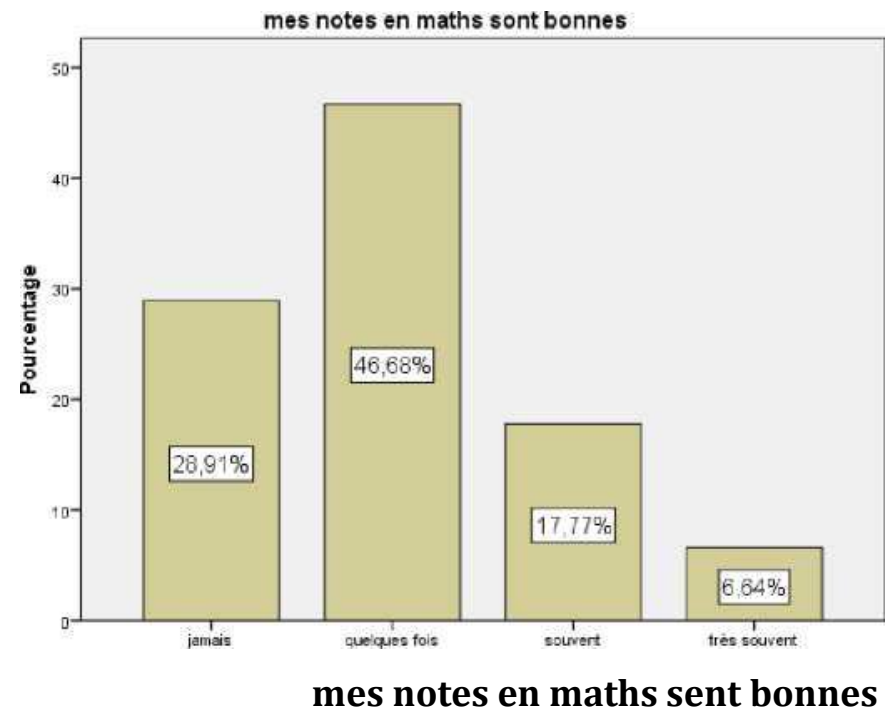

Figure 2: Distribution of students according to the frequency with which they have good marks in mathematics.

Source: Surveys, 2019

The graph above indicates that the vast majority of students surveyed generally do not perform well in mathematics. In fact, almost half (46.68\%) of them report having good marks only a few times and a considerable proportion $(28.91 \%)$ say they never have good marks. Unlike them alone $(17.77 \%)$ say they often have good marks and a small minority (6.64\%) state that they very often have good marks. These results generally indicate the poor performance of students in this discipline.

\section{Metacognitive strategies implemented to solve a given mathematical problem}

The results of this study indicate that, in general, pupils encounter difficulties in mathematics from the class of Seconde (45.2\%). However, other students say that they have difficulty in mathematics from the fourth $(18.1 \%)$, sixth $(9.3 \%)$ or even from primary school (4.8\%) classes.

The figure below shows the different branches of mathematics (Geometry, Algebra, Analysis and Statistical Probability) in which students have the most difficulty. 


\section{Dans quelle(s) branche(s) des mathematiques avez-vous le plus de problemes}

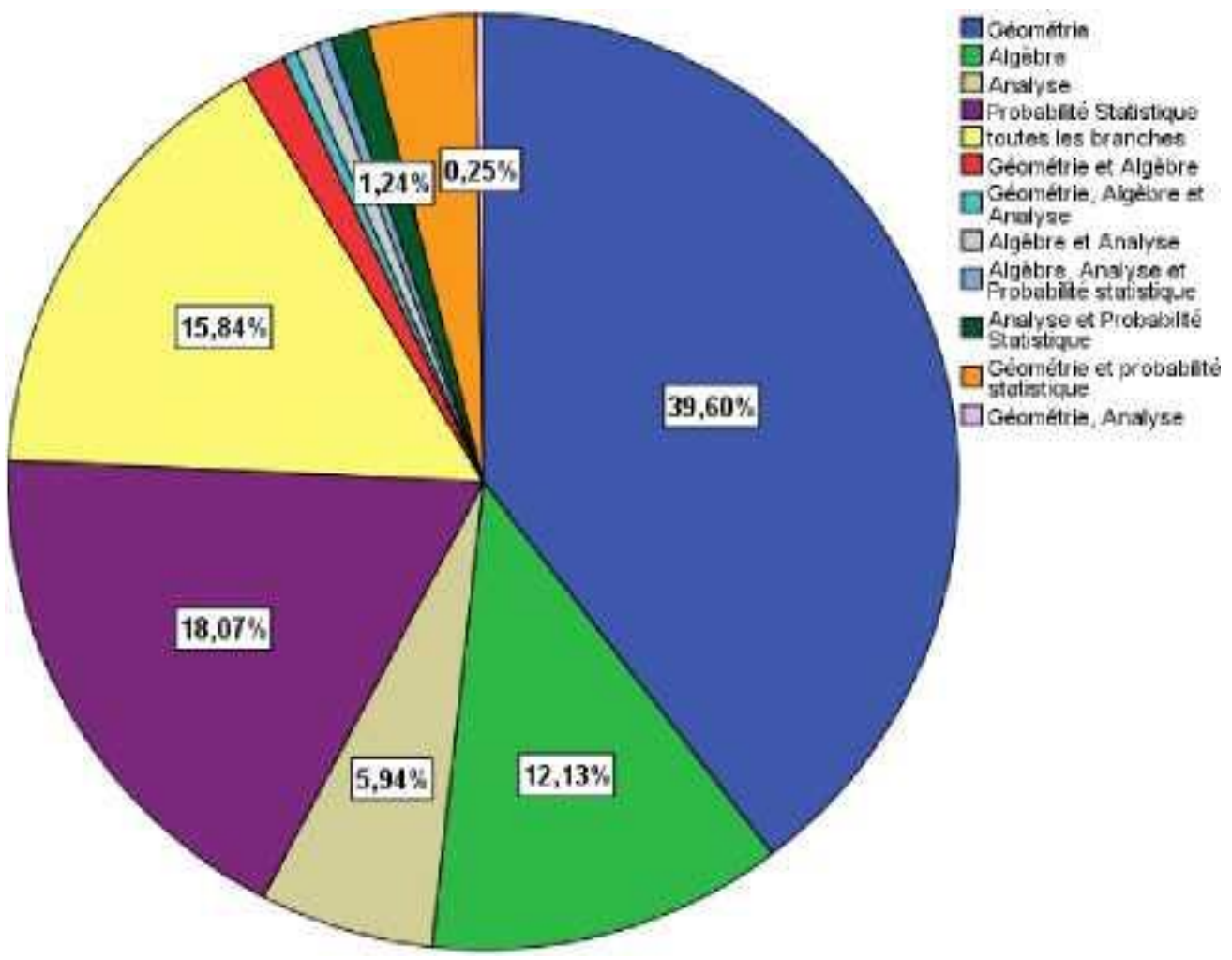

Figure 3: Distribution of respondents according to the branch (es) of mathematics in which they encounter the most problems.

Source: Surveys, 2019

According to the statistics presented in this figure, a high proportion $(39.60 \%)$ of the students questioned say they have more difficulties in Geometry, followed by those who say they have difficulties in Statistical Probability (18.07\%) and Algebra (12, $13 \%)$. However, a non- negligible proportion (15.84\%) of respondents indicate having difficulties in all branches of mathematics. It emerges from this analysis that Geometry constitutes the branch in which students encounter the most difficulties.

The difficulties encountered by pupils in the different branches of mathematics lie on several levels. It involves: calculations, demonstrations, understanding the symbols used in mathematics and integrating several learnings into a task. 


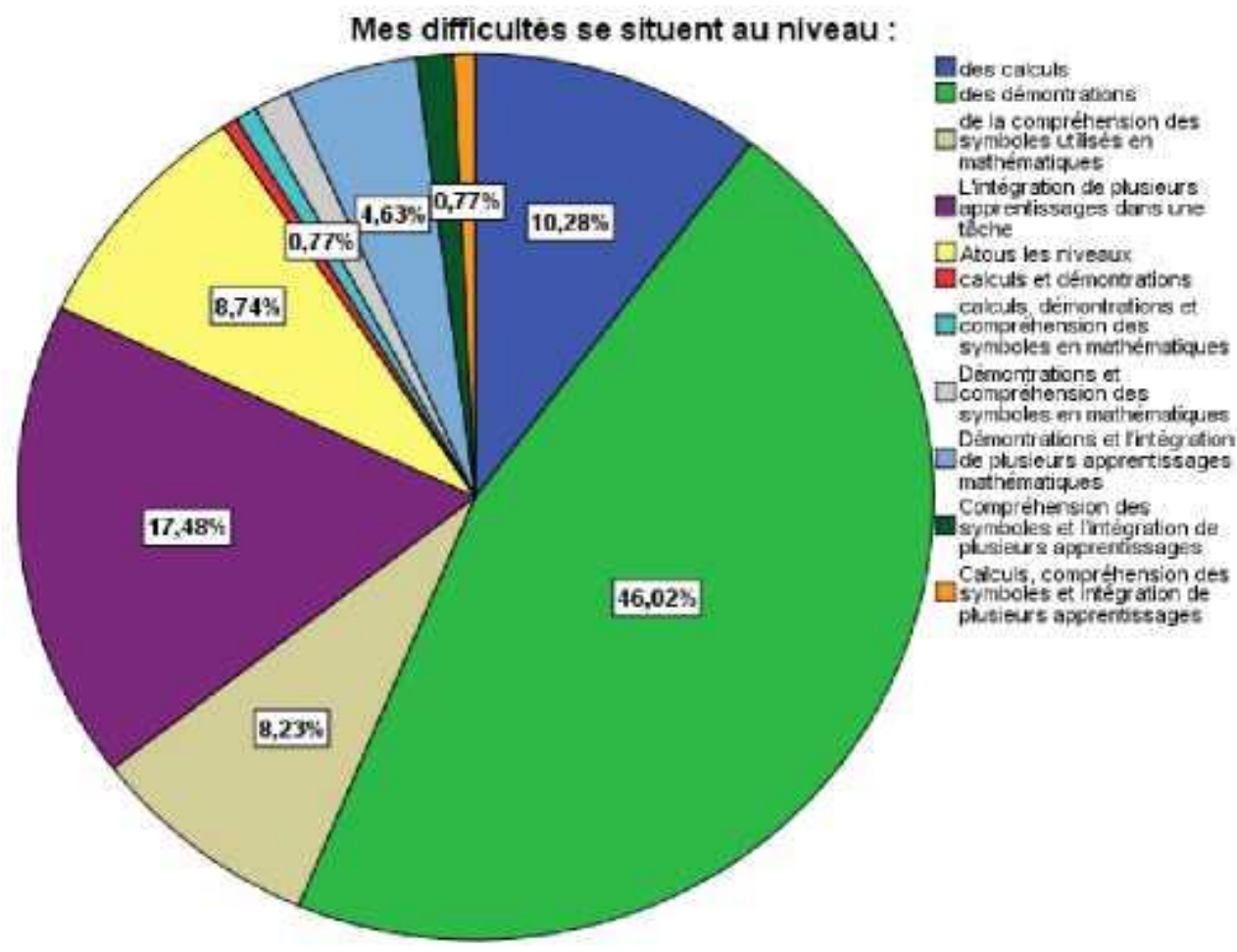

Figure 4: Distribution of respondents according to the type of difficulties they encounter in mathematics

Source: Surveys, 2019

The statistical data presented in this figure indicate that a fairly high proportion $(46.02 \%)$ of students say they have difficulties with demonstrations. Similarly, another sizeable proportion $(17.48 \%)$ of students say they encounter difficulties in integrating several learnings into a task. However, a small proportion $(8.23 \%)$ of respondents say they have difficulties relating to the understanding of symbols used in mathematics. Next to these pupils who have specific difficulties, $8.74 \%$ of pupils declare having difficulties at all levels.

It should be noted from this analysis that demonstrations in mathematics are a real concern for students, regardless of their level of study and their age.

\section{Metacognitive strategies implemented by the student to solve a given mathematical problem}

Most metacognitive knowledge concerns interactions between different variables, for example, the person, the task and the strategies (Flavell, 1979; Pinard, LefebvrePinard and Bibeau, 1989). Several metacognitive strategies are adopted differently by students to solve a given problem in mathematics. These are among others: the 
resolution of the next question before the one preceding it, the comparison of the question to be treated with a similar question already encountered, the contextualization of the question asked and the cognitive summary of what is done and what remains to be done.

\section{Resolution of questions in the order of arrangement in the problem statement}

Students adopt various metacognitive strategies in solving a problem. Along the way, some students allow themselves to be guided by the order induced by the utterance, while others adopt strategies which consist in resolving the questions according to their levels of apprehension of them.

\section{Dans la resolution d'un probleme je traite les questions sulvant I'odre dans} I'enonce

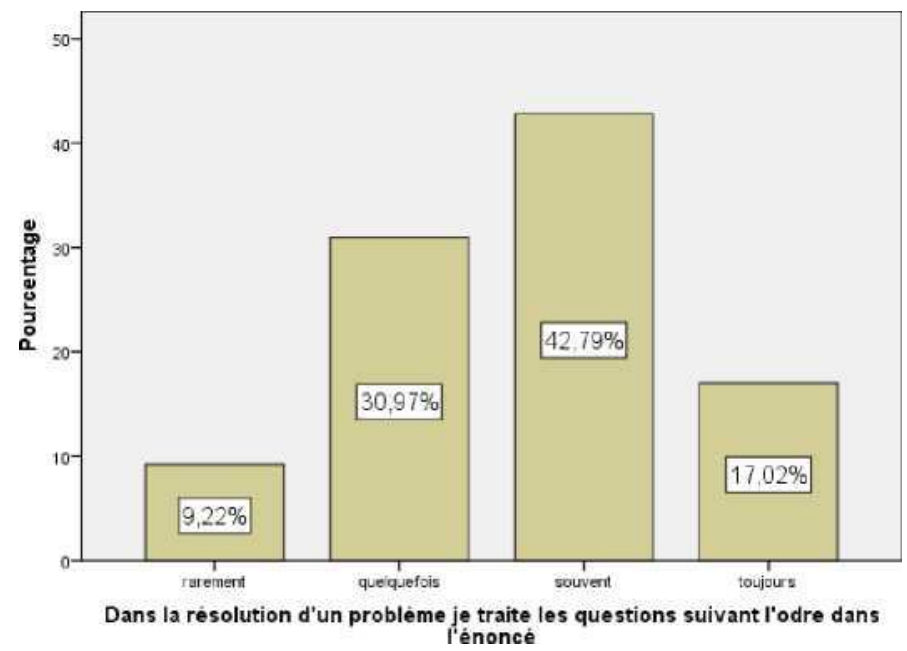

Figure 5: Graph of distribution of respondents according to the frequency with which they follow the order of the questions in the statement when solving the problem.

Source: Surveys, 2019

Figure 5 above indicates that the majority (cumulative percentage: 59.51\%) of students say they answer the questions often or always in the order in the statement and a considerable proportion (30.9\%) say they address the questions sometimes following the order induced by the statement. in contrast to these, it is noted that only a minority $(9.22 \%)$ claim to rarely do so. These data show that very few students adopt path strategies based on the difficulties they encounter when solving problems.

\section{Resolving the next question before the one before it}

One of the metacognitive strategies developed by the students interviewed during this study, is the resolution of the next question before the one before it when difficulties arise in understanding it. 
Table 1: Distribution of respondents according to the frequency with which they solve the next question before returning to the previous question.

\begin{tabular}{|c|c|c|c|c|}
\hline & Frequency & Percentage & Valid Percentage & Cumulative Percentage \\
\hline Very often & 149 & 35,2 & 35,2 & 35,2 \\
\hline Regularly & 137 & 32,4 & 32,4 & 67,6 \\
\hline Sometimes & 91 & 21,5 & 21,5 & 89,1 \\
\hline Very rarely & 46 & 10,9 & 10,9 & 100,0 \\
\hline Total & 423 & 100,0 & 100,0 & \\
\hline
\end{tabular}

Source: Surveys, 2019

According to the results presented in this table, $89.1 \%$ of students state that very often (35.2\%), regularly (32.4\%) or sometimes $(21.5 \%)$, when solving certain math problems, when the order of the questions hinders them in their progress, they sometimes resolve the following question (s) before returning to the previous question.

However, a small proportion (10.9\%) declare that they rarely do so. In the same vein, a very high proportion of the students surveyed (81.9\%) specifies that very often $(28.2 \%)$, regularly $(27.4 \%)$ or sometimes $(26.3 \%)$, when they do not immediately understand what is asked in a problem, they prefer to move on to the next question, while hoping that the problem will resolve itself. This approach is very rarely adopted by a small proportion $(18.1 \%)$ of students. The above results indicate that at least $10 \%$ of students follow the order in which the questions are asked in the statement to progress the resolution of the problem. And this despite the difficulties encountered. These are students who are very dependent on the structuring (the order) of the questions. We also note that the fact of redefining the order of resolution of the questions asked does not inexorably lead the student to a failure in solving the problem. In fact, $75 \%$ of respondents say that the failure to solve a problem is not due to the fact that they do not appear in the order in which certain questions are asked in the statement. It should be noted, however, that a significant proportion (25\%) of respondents said the opposite.

However, the bivariate analysis of the variables linked to the items "in solving a problem I treat the questions according to the order in the statement" and I follow a sequence of instructions "shows that:

Among students who rarely follow the order of questions, $12.8 \%$ rarely adopt, $20.5 \%$ sometimes adopt, $43.6 \%$ often adopt and $23.1 \%$ always follow a procedure according to the instructions.

Among the students who state that they sometimes follow the order of questions, $35.1 \%$ rarely adopt, $31.3 \%$ sometimes adopt, $23.7 \%$ often adopt and $9.9 \%$ always follow a procedure according to the instructions 
Among the students who state that they often follow the order of the questions, $47.5 \%$ rarely adopt, $37 \%$ sometimes adopt, $6.6 \%$ often adopt and $8.8 \%$ always follow a procedure according to the instructions

Among students who say they always follow the order of the questions, $51.4 \%$ rarely adopt, $33.3 \%$ sometimes adopt, $11.1 \%$ often adopt and $4.2 \%$ always follow a procedure as instructed.

Thus, students who very often or always follow the order of the questions in the statement adopt a path that varies rarely or sometimes, depending on the instructions of the statement. Conversely, those who rarely or sometimes follow the order of the questions often or always adapt their progress to the instructions given in the statement.

The chi-square test indicates that at the threshold $a=5 \%$, the order of succession of the questions in the statement of a mathematical problem has an impact on the student's cognitive path logic in solving this problem. . Indeed, the $p$-value $=0.000$ (the probability of making an error by rejecting the null hypothesis) being less than 0.05 , we can reject the null hypothesis of independence between the cognitive progress of the student and the order questions in the statement.

This situation highlights the influence of the teacher's logic in the structuring "previous question, next question" of the statement of a mathematical problem on that of the student in the resolution of this problem

Comparison of the question to be addressed with a similar question already encountered

Another strategy adopted is the comparison of the question to be treated with a similar question already encountered.

Table 2: Distribution of respondents according to whether they are trying to see how they can use the result obtained with the previous question to answer the next question.

\begin{tabular}{|l|l|l|l|l|}
\hline & Frequency & Percentage & valid Percentage & $\begin{array}{l}\text { Cumulative } \\
\text { Percentage }\end{array}$ \\
\hline Very often & 127 & 30,0 & 30,2 & 30,2 \\
\hline Regularly & 116 & 27,4 & 27,6 & 57,7 \\
\hline Sometimes & 124 & 29,3 & 29,5 & 87,2 \\
\hline Very rarely & 54 & 12,8 & 12,8 & 100,0 \\
\hline Total & 421 & 99,5 & 100,0 & \\
\hline No answer & 2 & & \\
\hline Total | 1423 & \multicolumn{2}{|l|}{0,5} & & \\
\hline
\end{tabular}

Source : Surveys, 2019 
According to the results presented in this table, a very high proportion of students $(87.2 \%)$ maintain that very often $(30.2 \%)$, regularly $(27.6 \%)$ or even sometimes $(29.5 \%)$, in a same exercise, when they do not immediately understand a question, they try to see if there are elements of answer in the previous question that could help them resolve the following question. Similarly, another way of proceeding is to ask whether the question to be dealt with does not refer to another already resolved question which is similar to it. This approach is very often (27.1\%), regularly (24.2\%) or even sometimes (30.2\%) adopted. Put together, they make up a very large majority $(81.5 \%)$ of the students interviewed for this study.

\section{Contextualization of the question asked}

The contextualization of the question asked is also one of the metacognitive strategies used by students to solve a given problem in mathematics. The table below provides more details.

Table 3: Distribution of respondents according to whether they are trying to understand a question using the situation in which it is asked.

\begin{tabular}{|l|l|l|l|l|}
\hline & Frequency & Percentage & valid Percentage & cumulative Pourcentage \\
\hline \multirow{2}{*}{$\begin{array}{l}\text { Very often } \\
\text { Regularly } \\
\text { Sometime Very } \\
\text { rarely Total }\end{array}$} & 140 & 33,1 & 33,3 & 33,3 \\
\cline { 2 - 5 } & 149 & 35,2 & 35,4 & 68,6 \\
\cline { 2 - 5 } & 103 & 24,3 & 24,5 & 93,1 \\
\cline { 2 - 5 } & 29 & 6,9 & 6,9 & 100,0 \\
\cline { 2 - 5 } & 421 & 99,5 & 100,0 & \\
\hline No answers & 2 &, 5 & & \\
\hline Total & 423 & 100,0 & & \\
\hline
\end{tabular}

Source: Surveys, 2019

According to the statistics presented in Table 3, almost all (93.1\%) of students maintain that very often (33.3\%), regularly (35.4\%) or even sometimes $(24.5 \%)$, when they do not immediately understand a question, they try to understand it using the situation in which it is asked. Unlike these, this strategy is very rarely adopted by a very small proportion (6.9\%) of the students surveyed.

\section{Cognitive summary of what is done and what remains to be done.}

Table 4: Distribution of respondents according to whether they summarize what they have already done and what remains to be done.

\begin{tabular}{|l|l|l|l|l|}
\hline & Frequence & Pourcentage & Pourcentage valide & Pourcentage cumule \\
\hline \multirow{2}{*}{$\begin{array}{l}\text { Very often } \\
\text { Regularly }\end{array}$} & 91 & 21,5 & 21,7 & 21,7 \\
\cline { 2 - 5 } $\begin{array}{l}\text { Sometimes Very } \\
\text { rarely Total }\end{array}$ & 138 & 32,6 & 32,9 & 54,5 \\
\cline { 2 - 5 } & 112 & 26,5 & 26,7 & 81,2 \\
\cline { 2 - 5 } & 79 & 18,7 & 18,8 & 100,0 \\
\hline
\end{tabular}




\begin{tabular}{|l|l|l|l|l|}
\hline & 420 & 99,3 & 100,0 & \\
\hline No answers & 3 & 0,7 & & \\
\hline Total & 423 & 100,0 & & \\
\hline
\end{tabular}

Source: Surveys, 2019

According to the statistics in this table, $81.2 \%$ of respondents say that very often $(21.7 \%)$, regularly $(32.9 \%)$ or even sometimes $(26.7 \%)$, while they are solving a problem, they sum up in their " heads " what they have already done and what they still have to do. Even if in most cases students develop problem-solving strategies, it should be noted that when they do not understand the first question asked in a mathematical problem, they are often disturbed in their progress. Even when the questions that follow seem affordable to them.

Table 5: Distribution of respondents according to whether they are disturbed in their progress when they do not understand the first question.

\begin{tabular}{|l|l|l|l|l|}
\hline & Frequence & Pourcentage & Pourcentage valide & Pourcentage cumule \\
\hline \multirow{2}{*}{$\begin{array}{l}\text { Very often } \\
\text { Regularly } \\
\text { Sometimes Very } \\
\text { rarely Total }\end{array}$} & 115 & 27,2 & 27,2 & 27,2 \\
\cline { 2 - 5 } & 67 & 15,8 & 15,8 & 43,0 \\
\cline { 2 - 5 } & 174 & 41,1 & 41,1 & 84,2 \\
\cline { 2 - 5 } & 67 & 15,8 & 15,8 & 100,0 \\
\cline { 2 - 5 } & 423 & 100,0 & 100,0 & \\
\hline
\end{tabular}

Source: Surveys, 2019

According to the statistics presented in this table, $84.2 \%$ of respondents say that very often $(27.2 \%)$, regularly $(15.8 \%)$ or even sometimes $(41.1 \%)$, when they come up against the first question of a math exercise, they find it difficult to continue solving the exercise although the following questions are within their reach.

\section{Link between poor performance in mathematics and the discrepancy between the logic of resolution induced by the statement and that of the student facing the problem posed}

The bivariate analysis of the variables linked to the items "in solving a problem I deal with the questions according to the order in the statement" and "I have good marks in mathematics" shows that: - Among the students who state that they rarely deal with questions in the order in which they are stated, 30.8\% state that they never have good marks, $20.5 \%$ have sometimes, $23.1 \%$ have often and $10.3 \%$ very often good grades.

Among the students who state that they sometimes address the questions in the order in which they are stated, $28.2 \%$ state that they never have good marks, $54.2 \%$ have sometimes, $14.5 \%$ have often and $3.1 \%$ have very often good grades. 
Among the students who state that they often deal with the questions in the order in which they are stated, $28.9 \%$ state that they never have good marks, $45 \%$ have sometimes, $16.1 \%$ have often and $10 \%$ have very often, good marks.

Among the students who say they always deal with the questions in the correct order in the statement, $29.2 \%$ declare never having good marks, $43.1 \%$ have sometimes, $25 \%$ have often and $6.6 \%$ have very often, good grades.Thus, there are disparities in student performance in solving the questions of a problem, regardless of how often they follow the order of the questions in the statement. The Chi-square test also confirms that at the threshold of $a=0.05$, there is no relationship between students' performance in mathematics and the frequency with which they follow the order of the questions in the statement. Indeed, the value $p=0.099$ (probability of rejecting the null hypothesis when it is true) is greater than $\mathrm{a}=0.05$. So we cannot reject HO.

\section{Procedure for the teacher to elaborate the statement of a mathematical problem}

The results obtained from the teachers interviewed reveal that the procedure for developing the statement of a mathematical problem differs from one teacher to another. While some teachers take a relatively clear approach, others do not take any particular procedure into account. This is the case, for example, of Mr. Ka., A math teacher, who, in terms of procedure, only bases himself on things already seen by the learners to develop the statement of a problem in mathematics. This one affirms: "there is no particular rule applied in the structuring of the statement of the problem. It is a direct application of knowledge and skills". Abounding in the same direction, Mr. Y. maintains that: "To build a mathematical problem, I look at the course I did, I see the skills to develop, and then I give a subject that embraces all of these data ".

In contrast, other teachers develop problem statements in mathematics, taking into account certain criteria. This involves developing the mathematical problem around the skills sought, asking " small " questions, that is to say easy to solve, to put the student at ease, guiding him towards the essential skills that we want to evaluate and initiate an activity in order to get students to bring out the problem.

Another procedure is to construct the problem in mathematics, going from the most obvious skills to achieve to the most complex ones.

In general, it appears that most of the teachers interviewed avoided the questions being linked so as not to have the student blocked in solving the problem. And even when the questions need to be linked, teachers ensure that the following questions use the answers from the previous questions, which are subtly presented as data to be used. This assertion is supported by the words of Mr. K., math teacher, who says: "The student is not necessarily asked to follow the order in which the math problem is posed to arrive at the expected answer. He can even see his own approach, while taking into account the requirements of the program in force". When analyzing these remarks, it should be noted that teachers admit that students sometimes follow their own path 
to achieve the expected result, provided that this path is consistent with the program in force.

Another strategy used by teachers is to deal with the subject at home or even seek the advice of their colleagues in order to correct any inconsistencies in the writing of the statement, before submitting it to the students for reflection.

These teachers point out that the area where students have the most problems is geometry. Particularly for the students of final grade, the problem is in arithmetic. Because they have real difficulties in correctly representing the problem posed in order to adopt a good resolution strategy.

\section{Discussion and Conclusion}

The results of this study corroborate those of numerous studies by researchers who have demonstrated that problem solving is an activity which requires the subject to construct an effective path in order to arrive at the adequate solution. As Poirier Proulx (1999) points out, problem solving is a "thinking strategy which consists in seeking a path to reduce the gap between a present unsatisfactory situation and a desired satisfactory situation or a goal to be achieved". The study highlights concordances but also divergences in the student's path when solving a given problem, with the teacher's logic in the arrangement of the questions asked.

Problem solving is an essential process in learning mathematics. it allows students to learn how to use and explain their own strategies and to recognize that several very different strategies lead to the same solution (Education in Ontario Paper 2, 2006); Thus, to solve a given mathematical problem, students have recourse to various metacognitive strategies, more particularly self-regulation: the resolution of the next question before the one that precedes it when it appears more difficult, the comparison of the question to be treated with a similar question already encountered, the contextualization of the question asked and the cognitive summary of what is done and what remains to be done. These results corroborate those of Flavell, 1979; Pinard, Lefebvre-Pinard and Bibeau, 1989.

The results also indicate that the vast majority of students surveyed generally do not perform well in mathematics. In addition, the difficulties encountered by pupils in mathematics generally arise from the second grade. It should be noted from this study that the calculations, the demonstrations, the understanding of the symbols used in mathematics and the integration of several learnings in a task represent difficulties for the pupils in the various branches of mathematics. However, according to the teachers surveyed, geometry is the area in which students have the most difficulty solving problems.

However, it should be noted that demonstrations in mathematics are a real concern for students, regardless of their level of study and their age. Regarding the procedure for developing the statement of a mathematical problem in general, it emerges that 
most of the teachers interviewed avoided that the questions were linked so as not to have the student be blocked in his progress by one or more some questions he does not understand. And even when the questions need to be linked, teachers ensure that the following questions use the answers from the previous questions, which are subtly presented as data to be used. These results corroborate those of De Vanssay S. and Blavous S. (2010), who emphasize the structuring of the content of a mathematical statement, aimed at guiding the student in his resolution. This situation highlights the impact of the teacher's logic in structuring "previous question, next question " in the statement of a mathematical problem, on that of the student in solving this problem.

Furthermore, it should also be noted that the performance of students in mathematics is not dependent on the frequency with which they follow the order of the questions in the statement. Ultimately, it should be noted that the results of this study contain some weaknesses, due to the data collection instruments, the survey sample, the conditions under which these information collections were carried out, the processing of the data collected. And the interpretation of the results obtained. We must therefore be careful not to generalize them haphazardly. However, they should not be dismissed out of hand.

\section{Bibliography}

[1] Barbier, J.-M. (1984). Training evaluation. Paris: PUF.

[2] Brassard, N. (2012). Evaluation and feedback: how to benefit from it? the $\begin{array}{llllll}\text { painting } & \text { volume } & 1 & \text { number } & 4 & -\end{array}$ https://www.seigner.ulaval.ca/ressources- pedagogiques/la-strategie-devaluation

[3] Brun, J. (1990). "Solving arithmetic problems: assessment and perspectives". Maths- ecoles, $\mathrm{n}^{\circ} 141$

[4] Couchoux, C. (2005). Schematic aids problem solving. IUFM de BOURGOGNE, Final thesis.

[5] De Blavous, S. (2010). An example of teaching practice for solving additive problems in CE1; Why be complex when you could be simple? Dissertation of Master 1 sciences of education University Paris Descartes

[6] Education in Ontario (2006). Guide to Effective Mathematics, Kindergarten to Grade 6 Leaflet 2, Ontario

[7] Fagnant, A., Richard, E., Mottier-Lopez, L. \& Hindryckx, M-N (2017). Assessment as a learning object and as a professional development tool in the context of teacher training. Evaluate- International Journal of Research in Education and Training, Lodel. <hal-01715665>.

[8] Flavell, J. H. (1979). Metacognition and cognitive monitoring. American 
Psychologist, 34 (10).

[9] Kalamo, A. (2010/2011). Determinants of school performance at the end of elementary education in Senegal: Case of the Departmental Inspectorate of Education in Velingara, in the Kolda region. Master, thesis in education and training CHEIKH ANTA DIOP DAKAR UNIVERSITY (UCAD).

[10]THE DICO OF DEFINITIONS (2011). Problem definition. URL: https://lesdefinitions.fr/probleme

[12]Le Robert, P. (2003). Alphabetical and analogical dictionary of the French language. Paris: Petit Robert.

[13] Legendre, R. (1993). Current dictionary of education. Paris: Eska.

[14] Munck, F. Pilard, P. \& Terrien, D. (2014). Evaluate to make students succeed. the Nantes Academy reprography service of the Nantes rectorate (LoireAtlantique)

[15] Musial, M., Pradere, F. \& Tricot, A. (2012). How to design an education? Brussels: De Boeck.

[16]Pinard, A., Lefebvre-Pinard, M. and Bibeau, M. (1989). Metacognitive knowledge on understanding: comparison between illiterate adults and literate adults. Revue quebecoise de psychologie, 10 (3), 78-91

[17]Poirier Proulx, L. (1999). Problem solving in teaching. Reference framework and training tools. Paris: De Boeck and Larcier.

[18]Vergnaud, G. (1986). Psychology of cognitive development and didactics of Mathematics. Revue Grand N ${ }^{\circ} 38$; URL: http://jean-luc.bregeon.pagespersoorange.fr/Page\%201-7.htm 